This article is licensed under the Creative Commons Attribution-NonCommercial 4.0 International License (CC BY-NC) (http://www.karger.com/Services/OpenAccessLicense). Usage and distribution for commercial purposes requires written permission.

\title{
Effects of Long-Term Treatment with T-PEMF on Forearm Muscle Activation and Motor Function in Parkinson's Disease
}

\author{
Bente Rona Jensen ${ }^{a, b} \quad$ Anne Sofie Bøgh Malling ${ }^{a, b} \quad$ Bo Mohr Morberg ${ }^{a, b}$ \\ Ole Gredal ${ }^{c} \quad$ Per Bech $^{d}$ Lene Wermuth ${ }^{a, b}$ \\ aDepartment of Neurology, Odense University Hospital, University of Southern Denmark, \\ Odense, Denmark; ${ }^{b}$ Department of Clinical Research, University of Southern Denmark, \\ Odense, Denmark; 'The Danish Rehabilitation Centre for Neuromuscular Diseases,

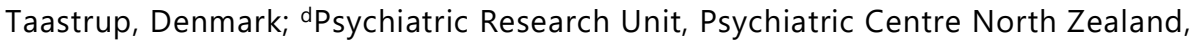 \\ University of Copenhagen, Hillerød, Denmark
}

\section{Keywords}

Parkinsonism · Motor deficiency · Transcranial pulsed electromagnetic stimulation · Tremor . Handwriting $\cdot$ EMG
Abstract
Bipolar pulsed electromagnetic stimulation applied to the brain (T-PEMF) is a non-pharmaco- logical treatment which has been shown to stimulate nerve growth, attenuate nerve abnor- malities, and improve microcirculation. We report on a 62 -year-old, medically well-treated man with idiopathic Parkinson's disease. He was treated with T-PEMF, 30 min per day for three 8- week periods separated by two 1 -week breaks. The disease made his handwriting impossible to read mainly due to small letters and lack of fluency. Forearm EMG measured during stand- ardized conditions showed an involuntary spiky EMG pattern with regular burst activity (on his left side) at baseline. The intervention normalized the handwriting and forearm EMG. The 


\section{Case Reports in Neurology}

Case Rep Neurol 2018;10:242-251

DOI: $10.1159 / 000492486$

(c) 2018 The Author(s). Published by S. Karger AG, Basel www.karger.com/crn

Jensen et al.: T-PEMF Treatment in PD

UPDRS-motor score decreased from 25 to 17, and UPDRS-II-handwriting decreased from a pre-intervention value of 3 to 0 after the intervention. Finally, the patient reported improved fine motor function, less muscle stiffness, less muscle cramps and tingling, and less fatigue during the day in response to the T-PEMF treatment. The improved handwriting lasted for approximately 3 months after the treatment. Our results should be considered as preliminary, and large-scale, controlled studies are recommended to elucidate the therapeutic potential of long-term treatment with T-PEMF.

(C) 2018 The Author(s)

Published by S. Karger AG, Basel

\section{Background}

Impaired fine motor skills and tremor are common in Parkinson's disease (PD). It is commonly accepted that the origin of the tremor is in the central nervous system, although the exact pathophysiological mechanisms leading to Parkinsonian tremor are still discussed. Several hypotheses regarding the origin of tremor have been proposed in the literature. There seems to be evidence that both the basal ganglia and the cerebello-thalamo-cortical loop are involved in Parkinsonian tremor. Activity in the basal ganglia is primarily affected by dopamine depletion in PD. Recently, a new model, the "dimmer-switch-model," has been proposed. The model combines features of previous hypotheses into a complex model. The dimmerswitch-model explains tremor as resulting from the combined action of two neural circuits: the basal ganglia that trigger tremor-related responses in the cerebello-thalamo-cortical circuit initiate the tremor (switch) and the cerebello-thalamo-cortical circuit produces the tremor and modulates tremor intensity (dimmer). Further, the model suggests that these interactions occur in the motor cortex where the two circuits converge $[1,2]$. Tremor is associated with rhythmic, bursty, neuronal firing and is clearly visible on surface electromyographic (EMG) recordings [3].

Treatment with bipolar pulsed electromagnetic fields (PEMF) is a non-invasive, rapidly emerging technique. The biophysical effects of PEMF are to depolarize the membrane potential slightly and to induce ion currents in the tissue [4]. The technique (in animals and in vitro) seems to enhance cellular activity and stimulate growth-related responses and regeneration [4]. For example, PEMF has been shown to stimulate nerve growth and attenuate nerve abnormalities, to increase the microvascular blood flow and tissue oxygenation, and to increase capillary density [5-8]. Thus, a connection between pulsed electromagnetic fields and the physiological response must exist. Treatment with PEMF constitutes a new, potential, nonpharmacological treatment method of PD when applied transcranially to the brain (T-PEMF).

The patient presented in this case report participated in an ongoing study on the effects of long-term treatment with T-PEMF. In this study, we focus on tremor characteristics, muscle activation, and gross motor function in terms of movement speed and functional rate of force development. The reason why this particular patient is presented as a case report was that he produced a detailed written report on signs and symptoms and conducted writing tests during and after the treatment period on his own initiative and blinded to the researchers. The researchers received the patient report and the writing tests after the end of the treatment. These data raised the question whether there were any systematic changes in the activation of the forearm muscles in response to the T-PEMF treatment that could be documented. 


\section{Case Reports in Neurology}

Case Rep Neurol 2018;10:242-251

DOI: $10.1159 / 000492486$

(c) 2018 The Author(s). Published by S. Karger AG, Basel www.karger.com/crn

Jensen et al.: T-PEMF Treatment in PD

\section{Case Report}

We report on a male patient (age 62 years, body weight $73 \mathrm{~kg}$, height $1.77 \mathrm{~m}$ ) who had been diagnosed with PD according to the UK Brain Bank criteria 6 years prior to participation. Total score of the Unified Parkinson Disease Rating Scale (UPDRS) was 50, UPDRS-motor was 25, UPDRS-II-handwriting was 3, Hoehn and Yahr stage was 2, and Mini-Mental State Examination score was 30 at baseline. The patient was left-handed, and the left side was most affected. The patient received $1,010 \mathrm{mg} / 24 \mathrm{~h}$ levodopa equivalent dose (Selegeline, Ropinirole, levodopa/benserazide). The patient was medically well-treated, and the medication had not been changed for more than 6 weeks prior to or throughout the T-PEMF intervention period. The patient had no family history of PD. The patient's handwriting was characterized by diminution of letter size, a tendency to progressive reduction in size, and lack of fluency, which made his handwriting unreadable at baseline.

The patient was treated with T-PEMF (home-based) in three periods of 8 weeks' duration separated by a 1 -week pause between the treatment periods. Thus, the total intervention period was 26 weeks. Each treatment period included one daily treatment of 30 min duration. No sham treatment was performed. T-PEMF was performed through 7 coils placed in a helmet-like shape, with one coil in the central occipital region, one in the frontal-parietal region (bilateral), and two in the anterior-temporal and posterior-temporal region (bilateral) (Re5 NTS Parkinson Treatment System, Re5, Frederiksberg, Denmark). The coils were connected to an external pulse generator which generated bipolar, squared pulses (amplitude approximately $50 \mathrm{~V}$, duration $3 \mathrm{~ms}$, frequency $55 \mathrm{~Hz}$ ) to initiate rapid changes in the currents in the coils, which gave rise to a time-dependent, rapidly changing electromagnetic field. The electromagnetic field penetrates through electrically insulated tissue, such as, for example, the skull, and induces a driving force on the charged particles (peak E-field intensity approximately $2.5 \mathrm{mV} / \mathrm{cm}$ near the coil) and thereby electrical currents in the brain (Table 1).

The outcomes in the present case report are forearm muscle activation, handwriting performance, and reported observations. In addition, UPDRS was measured before and after the intervention. All measurements were performed in self-reported on-phase. Surface EMG (MQ15, Marq Medical, Denmark) was recorded from wrist/finger extensor and wrist flexor muscles (bilaterally). EMG was recorded with the patient seated on a chair (no back support), the shoulders 90 degrees flexed, elbows stretched, arms parallel, palms facing the floor, and an external load of $0.480 \mathrm{~kg}$ in each hand (power grip). EMG was measured at baseline (week 0), after 2 periods of T-PEMF treatment (week 17), and on the day after the last T-PEMF treatment (week 27). Measurements of EMG at the three time points during the treatment period were repeated twice for each time point. Each recording lasted $25 \mathrm{~s}$. Handwriting tests, performed during the treatment period, were saved by the patient and shown to the researchers after the end of the treatment. Observations regarding status and changes in motor and nonmotor signs and symptoms were reported by the patient and the patient's family. The reported observations were given in written form to the researchers after the end of the treatment. EMG results, handwriting tests, and patient observations are presented in Figures 1, 2, and 3, respectively. The total UPDRS score was 38, UPDRS-motor was 17, and UPDRS-II-handwriting was 0 after the intervention.

In addition, the patient performed writing tests at $2,7,11$, and 16 weeks after the treatment. The patient's improved writing performance was largely maintained for at least 11 


\section{Case Reports in Neurology}

Case Rep Neurol 2018;10:242-251

DOI: $10.1159 / 000492486$

(C) 2018 The Author(s). Published by S. Karger AG, Base www.karger.com/crn

Jensen et al.: T-PEMF Treatment in PD

weeks. At week 16 after the intervention, a marked impairment was seen (online suppl. Fig.; for all online suppl. material, see www.karger.com/doi/10.1159/000492486).

\section{Discussion}

The patient had been diagnosed with PD 6 years prior to participation. Handwriting impairment was among the patient's first visible signs. Surface EMG was measured on the wrist extensor and flexor muscles during a bilateral, prolonged, low-level, static contraction. A static muscle activation pattern was, therefore, expected bilaterally, in both the extensor and flexor muscles, and with the highest activation level in the extensor muscles. The expected muscle activation pattern was found for the muscles on the right side, which was the patient's less affected side (Fig. 1). However, on the left side, a spiky EMG pattern with regular burst activity was measured in the extensor muscles and to some extends in the flexor muscles throughout the contractions at baseline. Such an EMG pattern is common in PD and can result in tremor. However, tremor is the mechanical manifestation of involuntary, intermittent muscle activation, and it occurs when the internal torque generated by the muscles exceeds the external torque generated by gravity. Thus, consequently, involuntary EMG burst activity can occur without visible tremor when the internal torque is less than the external torque. However, this type of involuntary muscle activation pattern can certainly disturb fine motor skills, such as, for example, writing ability, due to a lack of force and movement control.

Figure 2 shows the patient's handwriting performance at different time points. Handwriting is a complex motor activity, and dysfunction is a major and common disabling sign of PD, although not included in the diagnosis. In accordance, the lack of readability of his handwriting was a major problem for the patient at baseline. The patient's handwriting was significantly improved after the treatment period compared to baseline. This is, letter size was increased, and his writing was much more fluent and certainly readable. Handwriting disability is associated with decreased activity and connectivity in the basal ganglia motor circuit [9]. Furthermore, writing ability and tremor share a common correlate, dopamine, in PD [10-12]. Therefore, it is hypothesized that long-term treatment with T-PEMF increases the level of dopamine in the brain [13].

EMG measurements at week 17 clearly showed a changed activation pattern of the left forearm muscles compared to baseline. The spiky muscle activation pattern had disappeared, and a pattern corresponding to the right-side EMG was found. The same static activation pattern was found after the third 8-week treatment period. In parallel with this, the three 8-week periods of treatment with T-PEMF improved the readability and the quality of the patient's handwriting significantly as shown in Figure 2. In accordance, UPDRS-II-handwriting was reduced from 3 to 0 during the treatment period. The major improvement was found after the first two 8-week periods of treatment.

In addition, the patient reported improved fine motor function, less muscle stiffness, and less muscle cramps and tingling in response to the T-PEMF treatment. Furthermore, he experienced less fatigue during day time and became happier (Fig. 3). The improved writing ability after the treatment lasted approximately 3 months, indicating a long-term effect.

The present T-PEMF treatment differs significantly from rTMS regarding number of stimulation sites, intensity, frequency, stimuli per session, number of sessions, duration, and 
location (Table 1) $[14,15]$. Thus, T-PEMF induces a high number of weak, pulsating, electric fields in the brain tissue. The electric field is strong enough to cause protein activation but weaker than the limit for eliciting action potentials of brain cells and for opening voltage-dependent $\mathrm{Na}^{+}$channels [4].

In conclusion, it seems likely that the improved motor control, e.g., writing ability, is associated with the present normalization of forearm muscle activation and that this is an effect of long-term treatment with T-PEMF. The presented results should be considered as preliminary, and the effects of T-PEMF should be studied in large-scale, controlled studies to elucidate the therapeutic potential of the new technique.

\section{Acknowledgement}

We thank the patient for letting us publish his case and Meaghan Spedden for technical assistance.

\section{Statement of Ethics}

Written informed consent was obtained from the patient for his participation in this case report. The study was approved by the Ethics Committee, Project-ID: S-20160106.

\section{Disclosure Statement}

The authors have nothing to declare.

\section{Funding Sources}

The research group received funding from The Jascha Foundation, Denmark, Den A.P. Møllerske Støttefond, Copenhagen, Denmark, and Grosserer L.F. Foghts Foundation, Charlottenlund, Denmark.

\section{References}

1 Helmich RC, Janssen MJ, Oyen WJ, Bloem BR, Toni I. Pallidal dysfunction drives a cerebellothalamic circuit into Parkinson tremor. Ann Neurol. 2011 Feb;69(2):269-81.

2 Helmich RC, Hallett M, Deuschl G, Toni I, Bloem BR. Cerebral causes and consequences of parkinsonian resting tremor: a tale of two circuits? Brain. 2012 Nov;135(Pt 11):3206-26.

3 Zhang J, Xing Y, Ma X, Feng L. Differential diagnosis of Parkinson's disease, essential tremor, and enhanced physiological tremor with the tremor analysis of EMG. Parkinsons Dis. 2017;2017:1597907.

4 Rahbek UL, Tritsaris K, Dissing S. Interaction of low-frequency, pulsed electromagnetic fields with living tissue: biochemical responses and clinical results. Oral Biosci Med. 2005;2:1-12.

5 Pan Y, Dong Y, Hou W, Ji Z, Zhi K, Yin Z, et al. Effects of PEMF on microcirculation and angiogenesis in a model of acute hindlimb ischemia in diabetic rats. Bioelectromagnetics. 2013 Apr;34(3):180-8. 
6 Lei T, Jing D, Xie K, Jiang M, Li F, Cai J, et al. Therapeutic effects of $15 \mathrm{~Hz}$ pulsed electromagnetic field on diabetic peripheral neuropathy in streptozotocin-treated rats. PLoS One. 2013 Apr;8(4):e61414.

7 Hei WH, Byun SH, Kim JS, Kim S, Seo YK, Park JC, et al. Effects of electromagnetic field (PEMF) exposure at different frequency and duration on the peripheral nerve regeneration: in vitro and in vivo study. Int J Neurosci. 2016 Aug;126(8):739-48.

8 Urnukhsaikhan E, Cho H, Mishig-Ochir T, Seo YK, Park JK. Pulsed electromagnetic fields promote survival and neuronal differentiation of human BM-MSCs. Life Sci. 2016 Apr;151:130-8.

9 Wu T, Zhang J, Hallett M, Feng T, Hou Y, Chan P. Neural correlates underlying micrographia in Parkinson's disease. Brain. 2016 Jan;139(Pt 1):144-60.

10 Lange KW, Mecklinger L, Walitza S, Becker G, Gerlach M, Naumann M, et al. Brain dopamine and kinematics of graphomotor functions. Hum Mov Sci. 2006 Oct;25(4-5):492-509.

11 Dovzhenok A, Rubchinsky LL. On the origin of tremor in Parkinson's disease. PLoS One. 2012;7(7):e41598.

12 Dirkx MF, den Ouden HE, Aarts E, Timmer MH, Bloem BR, Toni I, et al. Dopamine controls Parkinson's tremor by inhibiting the cerebellar thalamus. Brain. 2017 Mar;140(3):721-34.

13 Strafella AP, Paus T, Fraraccio M, Dagher A. Striatal dopamine release induced by repetitive transcranial magnetic stimulation of the human motor cortex. Brain. 2003 Dec;126(Pt 12):2609-15.

14 Wagle Shukla A, Shuster JJ, Chung JW, Vaillancourt DE, Patten C, Ostrem J, et al. Repetitive transcranial magnetic stimulation (rTMS) therapy in Parkinson disease: A meta-analysis. PM R. 2016 Apr;8(4):356-66.

15 Chung CL, Mak MK. Effect of Repetitive transcranial magnetic stimulation on physical function and motor signs in Parkinson's disease: a systematic review and meta-analysis. Brain Stimul. 2016 Jul-Aug;9(4):47587.

Per Bech has deceased. 


\section{Case Reports in Neurology}

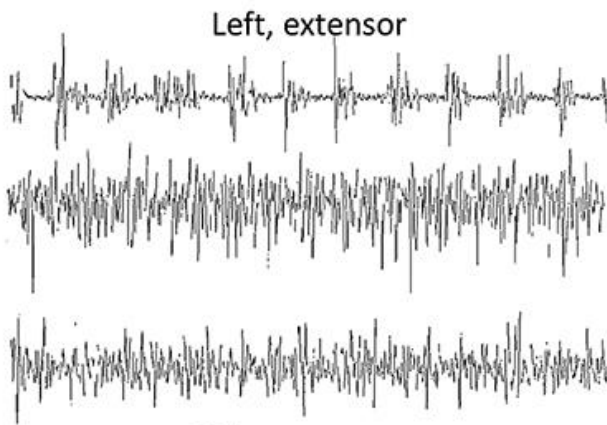

Week Left, flexor

0

(c) 2018 The Author(s). Published by S. Karger AG, Basel www.karger.com/crn

Jensen et al.: T-PEMF Treatment in PD

Right, extensor

Right, flexor
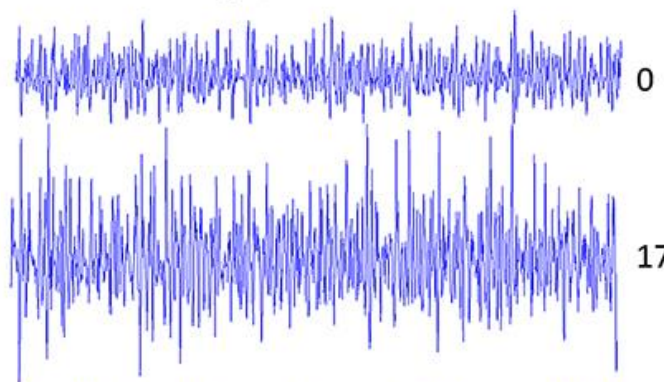

0

17

27

17
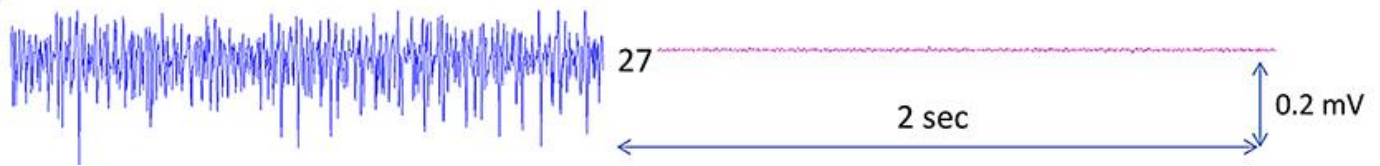

Fig. 1. EMG findings during a standardized, low-level, isometric contraction. Surface EMG recorded from the forearm extensor and flexor muscles. 0, at baseline; 17, after two 8-week periods with T-PEMF treatment; 27, after three 8-week periods with T-PEMF treatment. 


\section{Case Reports in Neurology}

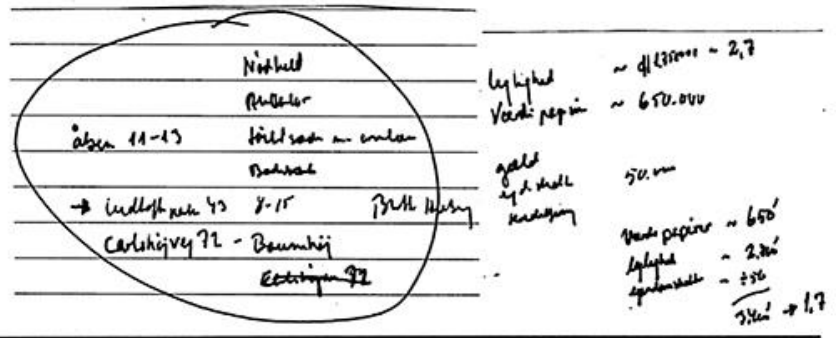

Whe sidder of kigge nd of cindent. Det or

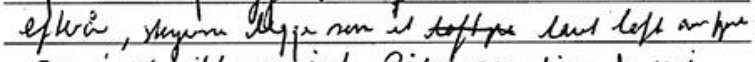

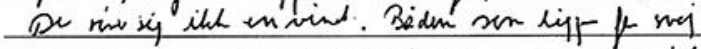

Jensen et al: T-PEMF Treatment in PD

(C) 2018 The Author(s). Published by S. Karger AG, Basel www.karger.com/crn

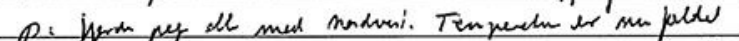

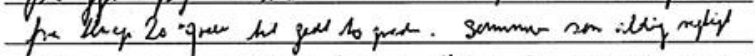

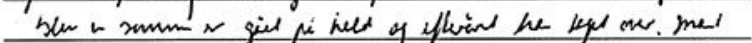

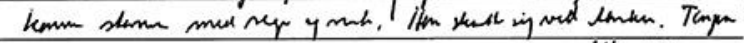

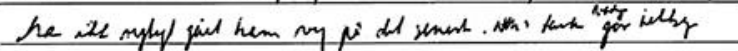

b

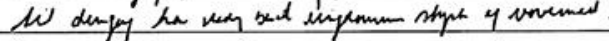

c

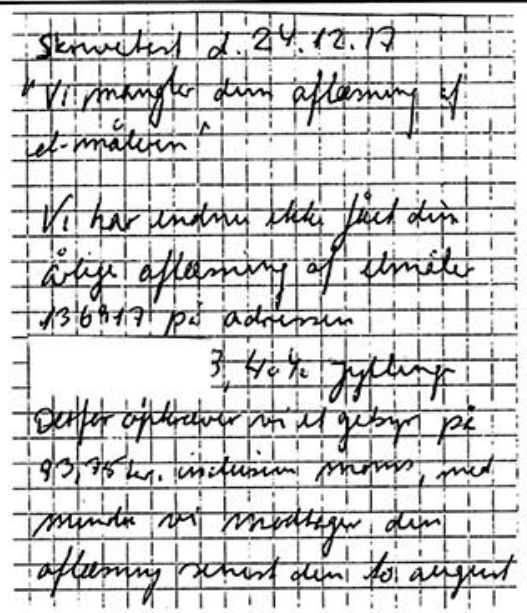

Fig. 2. Handwriting performed before, during, and after the treatment with T-PEMF. a Micrographia before the initiation of the treatment. $\mathbf{b}$ Handwriting test performed after the first two treatment periods. Letter size has increased significantly. c Handwriting test performed after the end of the treatment. The patient's handwriting is now normalized. 


\section{Patient report.}

For the first seven weeks of period one, nothing is seported. In the end of the first treatment period (week eight) the patient noticed that he was able to brush his teeth with a manual tooth brush again. This had not been possible for more than twa years. In the first pause (week nine) frequent muscle cramps and tingling which ocrurred both during day time and night was noticed. At thot time the potient became awore that these cramps and tingling had been significantly reduced in the last part of treatment period one.

The muscle cromps and tingling disappeared almost completely during the first weeks of treatment period two.

in treatment period 2 , week 3 , the family noticed the patient had been in a much better mood for the last three weeks.

The patient tried to write a text with a pen (period 2, week 3). The written text was now readable. The patient had not been able to read his own handwritten notes for 4-5 years (figure 3 )

The handwriting was repeated in treatment period two, week 5 . The written text was still readabje.

Treatment period 2, week 7 . The patient report less muscie stiffness and tenseness. The patient plays gaif and had observed that his golf swing had become more harmonic and coordinated. There is less muscle resistance.

The patient suffesed fram daily nausea. The periods with naused were more intense of ionger duration and more frequent hefore treatment with $T$ PEMF. The typical duration is now 15 minutes.

The patient experienced aggressive dreams associated with movements of arms and legs before the T-PEMF treatment was initiated. The intensity and frequency of these events were reduced significontly in response to the treatment.

Jreatment period 2, week 8 . Muscle cramp in the thigh muscie in the night after o $30 \mathrm{~km}$ bicycle ride.

Family and friends hove noticed that the potient is more aiert. The patient experiences that his muscles are less stiff and that they counteract each other to a lesser degree. The patient suffers from mild tremor. His tremor has now changed to some extend towards lower frequency and lorger ampitude.

Do still not sleep well at night.

The sleep period during daytime has been reduced from 1-1.5 hours to 0.5-1 hour.

Episodes of sudden blood pressure decrease are iess frequent. The patient reported that he is less constipated. Motor function is still improving. Reading still induces fatigue.

After treatment period 2 (2nd pause). I the beginning of the week the patient observed that he was able to close the zipper in his jacket while. walking. Before the treatment he had to stop walking in order to be able to close the zipper. Motor coordinotion is more natural and coordinated during running.

At the end af the week (2nd pouse) his speech become impaired again. This was reported by the wife. Pre-signs of muscle cramps had returned and the patient did not sleep well.

Treatment period 3, week 1: Muscle cromps at night.

Treatment period 3, week 3: Almost no muscie cramps. Less need to sleep during the day. The tremor is chonging again towards lower frequency and larger amplitude.

Treatment period 3, week 4+5+7+8: Nausea some days and a feeling of tingling in the legs. The patient had been sick for some days withaut any obvious reason. Less need to sieep during day time. The hand writing test was repeated in week 8

In summany, after the T-PEMF treatment period the patient was able to brush his teeth with a manual tooth brush and to ciose the zipper in his jacket while walking, both of which had not been possible for a long time. Furthermore, his handwriting had improved significantly and he experienced improved motor function compared to pre treatment. The experiences of fotigue during daytime and muscle cramps were reduced markedly. He was happier and much more active during conversations according to his fomily and himself.

Finally, the potient's tremor, which occurred when he was fatigued, changed in character to significantly lower frequency and iarger ampiitude. Unfortunately, the patient still did not sleep well during the night.

Fig. 3. Observations reported by the patient. 
Table 1. Characteristics of the presented T-PEMF stimulation method versus typical high-and low-frequency rTMS $[4,14,15]$

\begin{tabular}{|c|c|c|c|}
\hline & T-PEMF & High-frequency rTMS & Low-frequency rTMS \\
\hline Sites, $n$ & 7 & 1 (or 2) & 1 (or 2) \\
\hline Brain target & large & small & small \\
\hline Coil & circular & circular/figure 8 & circular/figure 8 \\
\hline Intensity & $\begin{array}{l}\text { about } 6 \text { th order of magni- } \\
\text { tude less than motor thresh- } \\
\text { old }\end{array}$ & $\begin{array}{l}\text { approximately active or } \\
\text {-rest motor threshold }\end{array}$ & $\begin{array}{l}\text { approximately active or } \\
\text { rest motor threshold }\end{array}$ \\
\hline Frequency, $\mathrm{Hz}$ & 55 & $5-25(50)$ & $\leq 1$ \\
\hline Stimuli/session & 99,000 & $450-3,000$ & $60-1,800$ \\
\hline Sessions (total) & 168 & $1-10$ & $1-10$ \\
\hline Duration & $3 \times 8$ weeks & 1 day to 8 weeks & 1 day to 8 weeks \\
\hline Treatment location & home & clinic & clinic \\
\hline
\end{tabular}

